JKEP

Vol 4, No 1, Mei 2019

ISSN: 2354-6042 (Print)

ISSN : 2354-6050 (Online)

\title{
Pengaruh Promosi Kesehatan Melalui Buku Praktis Kesehatan Ibu Hamil Preeklamsia Terhadap Pengetahuan Kader Kesehatan
}

\author{
Ulty Desmarnita, Yuli Mulyanti \\ Poltekkes Kemenkes Jakarta III \\ email: ultyhanafi@yahoo.co.id
}

\author{
Artikel history \\ Dikirim, Jan $17^{\text {th }}, 2019$ \\ Ditinjau, Feb 20 $0^{\text {th }}, 2019$ \\ Diterima, Maret 26, 2019
}

\begin{abstract}
Hypertension during pregnancy may lead to a serious condition called preeclampsia.Health cadre should be provided with information concerning identification of such risk. This study aimed to identify the impact of guidebook of pregnant woman with preeclampsia on knowledge and attitude in pregnant women in health cadre. The study design was quasi-experimental withnon-randomized pretestposttest group control approach. This study involved 60 health cadres whom were assigned into two groups, intervention group $(n=30)$ and control group $(n=30)$ and recruited through purposive sampling technique. The results suggest that there was significant difference in health cadre's attitude between both groups $(p=0.000)$. Variable of duration being a cadre is the most determinant factor affecting cadre's attitude. Health promotion through guidebook of pregnant woman with preeclampsia was effective in improving health cadre's attitude. Authors recommend health cadres to use the guidebook of pregnant woman with preeclampsia when enacting their duties.
\end{abstract}

Keywords: guidebook; preeclampsia;cadre; knowledge; attitude

\begin{abstract}
Abstrak
Hipertensi pada ibu hamil dapat menyebabkan kondisi serius yang disebut preeklamsia. Kader kesehatan perlu dibekali pengetahuan terkait cara mendeteksi risiko kehamilan tersebut. Penelitian ini bertujuan untuk mengetahui pengaruh promosi kesehatan melalui buku praktis kesehatan ibu hamil dengan preeklamsia terhadap pengetahuan dan sikap kader kesehatan. Desain penelitian ini adalah quasi experimental dengan pendekatan non randomized pretest-posttest group control. Penelitian ini melibatkan enam puluh kader yang dibagi menjadi dua kelompok, kelompok intervensi $(n=30)$ dan kelompok kontrol $(\mathrm{n}=30)$, yang diseleksi dengan teknik purposive sampling. Hasil penelitian menunjukkan terdapat perbedaan yang signifikan pada sikap kader antara kedua kelompok $(\mathrm{p}=$ 0.000).Variabel lama menjadi kader adalah faktor yang paling mempengaruhi sikap kader. Promosi kesehatan melalui buku praktis kesehatan ibu hamil dengan preeklamsia efektif dalam meningkatkan sikap kader. Rekomendasi peneliti agar buku pedoman kesehatan ibu hamil dengan preeklamsia digunakan oleh ibu kader kesehatan dalam menjalankan tugasnya.
\end{abstract}


Kata kunci: buku praktis; preeklamsia; kader; pengetahuan; sikap

\section{PENDAHULUAN}

Menurut WHO (2015), kematian ibu hamil masih sangat tinggi. Sekitar 830 ibu hamil meninggal akibat komplikasi terkait dengan kehamilan atau ketika melahirkan di seluruh dunia setiap harinya. Kementerian Kesehatan (2015) menyebutkan bahwa angka kematian ibu (AKI) mencapai 305 per 100 ribu kelahiran hidup. Kemenkes juga menyebutkan bahwa penyebab kematian ibu antara lain perdarahan, infeksi dan tekanan darah tinggi (eklampsi). Berdasarkan data Dinas Kesehatan Provinsi Jawa Tengah pada tahun 2012 tercatat kejadian angka kematian ibu karena preeklamsia/eklamsia sebanyak23,95\% (Dinkes Jateng, 2013).

Pre-eklamsia disebabkan oleh hipertensi gestasional, yaitu suatu kondisi yang ditandai dengan tekanan darah tinggi selama kehamilan (Kee-hak Lim, 2016). Hipertensi selama kehamilan diderita sekitar 6-8\% ibu hamil. Preeklamsia adalah gangguan karena malfungsi endothelial vaskular dan vasospasme yang terjadi setelah 20 minggu kehamilan dan dapat terjadi hingga 4-6 minggu postpartum. Preeklamsia dapat menimbulkan kerusakan organ lain, seperti hati, ginjal, jantung, dan otak, bahkan mengancam nyawa (Kee-hak Lim, 2016).

Pemerintah bersama masyarakat bertanggung jawab untuk menjamin bahwa setiap ibu memiliki akses terhadap pelayanan kesehatan ibu yang berkualitas, mulai dari saat hamil, pertolongan persalinan oleh tenaga kesehatan terlatih, dan perawatan pasca persalinan bagi ibu dan bayi. Selain fasilitas kesehatan dan tenaga kesehatan yang memadai, dalam menunjang upaya promosi kesehatan pada ibu hamil adalah peran kader kesehatan yang ada di posyandu.

Mikrajab \& Rahmawaty (2012) dalam penelitian mereka tentang Peran Kader Kesehatan dalam Program Perencanaan Persalinan dan Pencegahan Komplikasi (P4K) pada Ibu Hamil di Posyandu di Kota Mojokerto, Provinsi Jawa Timur menunjukkan bahwa peran kader dalam kegiatan P4K di Posyandu terkait penyuluhan dan target telah berjalan dengan baik, meskipun demikian, terdapat beberapa aspek peran kader kesehatan yang perlu ditingkatkan intensitasnya yaitu penyuluhan kepada 
dukun bayi, pemanfaatan buku KIA, serta penerapan sistem rujukan berjenjang pelayanan kesehatan maternal dalam $\mathrm{P} 4 \mathrm{~K}$.

Kusuma (2010), menunjukkan bahwa sebagian besar kader memiliki pengetahuan rendah sebanyak 38 responden $(61,3 \%)$ dan kader yang memiliki cakupan deteksi dini tidak tercapai sebanyak 45 responden (72,6\%). Simpulan penelitian didapatkan bahwa sebagian besar kader berpengetahuan rendah yang mengakibatkan tidak tercapainya cakupan deteksi dini risiko tinggi ibu hamil oleh kader. Oleh sebab itu, bidan puskesmas bersama-sama memberikan penyuluhan tentang deteksi dini risiko tinggi ibu hamil agar cakupan deteksi dini risiko tinggi ibu hamil oleh kader tercapai.

\section{METODE}

Penelitian ini adalah penelitian quasi experimental dengan pendekatan non randomized pretest-posttest with control group. Penelitian ini melibatkan 60 kader di Puskesmas Cipayung dan Cipinang Besar Utara dengan teknik purposive sampling. Jumlah tersebut dibagi sama rata yaitu 30 kader untuk masing-masing kelompok kontrol dan intervensi.Penelitian dilakukan dengan memberikan intervensi menggunakan buku praktis kesehatan ibu hamil dengan preeklamsi. pada kelompok intervensi dan membandingkan hasil intervensi dengan kelompok tanpa intervensi atau kelompok kontrol.

Instrumen yang digunakan adalah instrumen yang dikembangkan sendiri oleh peneliti berdasarkan kerangka teori.Instrumen tersebut mengukur pengetahuan kaderterkait preeklamsia. Penelitian ini dilaksanakan setelah mendapatkan ethical clearance dari Komite Etik Penelitian Poltekkes Kemenkes Jakarta III.

\section{HASIL DAN PEMBAHASAN}

Tabel 1.

Karakteristik Responden Berdasarkan Pendidikan, Pekerjaaan, Agama, Usia, dan Lama Menjadi Kader $(n=60)$

\begin{tabular}{|c|c|c|c|c|}
\hline \multirow[t]{2}{*}{ Variabel } & Kel.Intervensi & Kel.Kontrol & & \\
\hline & $\mathrm{N} \quad \%$ & $\mathrm{~N}$ & $\mathrm{~N}$ & $\%$ \\
\hline
\end{tabular}




\begin{tabular}{|c|c|c|c|c|c|c|}
\hline $\begin{array}{l}\text { 1. Pendidikan } \\
\text { Dasar }\end{array}$ & 10 & 33.3 & 5 & 16.7 & 15 & 25 \\
\hline $\begin{array}{l}\text { 2. Pendidikan } \\
\text { Menengah- } \\
\text { tinggi }\end{array}$ & 20 & 66.7 & 25 & 83.3 & 45 & 75 \\
\hline \multicolumn{7}{|l|}{ Pekerjaan } \\
\hline 1. IRT & 30 & 100 & 16 & 86.7 & 46 & 93.3 \\
\hline 2. Guru & - & - & 4 & 13.3 & 4 & 6.7 \\
\hline \multicolumn{7}{|l|}{ Agama } \\
\hline 1. Islam & 29 & 96.7 & 28 & 93.3 & 57 & 95 \\
\hline 2. K. Protestan & 1 & 3.3 & 2 & 6.7 & 3 & 5 \\
\hline \multicolumn{7}{|l|}{ Usia } \\
\hline 1. $<50$ thn & 14 & 46.7 & 16 & 53.3 & 30 & 50 \\
\hline 2. 50 thn ke atas & 16 & 53.3 & 14 & 46.7 & 30 & 50 \\
\hline \multicolumn{7}{|l|}{ Lama jd kader } \\
\hline 1. < 15 thn & 14 & 46.7 & 22 & 73.3 & 36 & 60 \\
\hline 2. 15 thn ke atas & 16 & 53.3 & 8 & 26.7 & 24 & 40 \\
\hline
\end{tabular}

Hasil analisis menunjukkan bahwa karakteristik kedua kelompok diatas yaitu kader usia kurang 50 thn, Ibu Rumah Tangga, berpendidikan menengah-tinggi, beragama Islam dan pengalaman jadi kader kurang dari 15 tahun. Usia tersebut masih memungkinkan daya ingat yang relatif baik (Benson dan Martin, 2009) , disamping itu dalam menjalankan tugas sebagai kader masih mempunyai energi yang baik pula. Menurut Kusumawardani (2010) bahwa semakin cukup umur kekuatan dan kematangan dalam bekerja dan berpikir lebih matang. Hal ini hampir sama menurut Widayat (2006) bahwa pendewasaan melalui pengalaman umur yang telah beradaptasi dengan lingkungan dapat merubah sikap dan perilaku. Masa atau lama menjadi kader sebagai faktor bagi kader mempunyai pengalaman terhadap apa yang dilakukan dalam tugas. Menurut Azwar (2011) pengalaman pribadi merupakan faktor dalam pembentukkan dan perubahan sikap seseorang, yang merupakan diferensiasi dalam pembentukkan tersebut.

Tabel 2. Perbedaan Pengetahuan dan Sikap Kader Sebelum dan Sesudah

\section{Intervensi}

\begin{tabular}{lllllll}
\hline Variabel & Kelompok & Mean & SD & $95 \%$ CI & t & P value \\
\hline
\end{tabular}




\begin{tabular}{|c|c|c|c|c|c|c|}
\hline \multirow[t]{2}{*}{ Pengetahuan } & $\begin{array}{l}\text { Kel. Intervensi } \\
\text { Sebelum } \\
\text { Sesudah } \\
\text { Selisih }\end{array}$ & $\begin{array}{l}46.77 \\
48 \\
1.233\end{array}$ & $\begin{array}{l}3.224 \\
3.824\end{array}$ & $0.207-2.673$ & 1.725 & 0.060 \\
\hline & $\begin{array}{l}\text { Kel. Kontrol } \\
\text { Sebelum } \\
\text { Sesudah } \\
\text { Selisih }\end{array}$ & $\begin{array}{l}49.50 \\
49.55 \\
0.267\end{array}$ & $\begin{array}{l}4.232 \\
4.150\end{array}$ & $2.026-1.493$ & 0.310 & 0.759 \\
\hline \multirow[t]{2}{*}{ Sikap } & $\begin{array}{l}\text { Kel. Intervensi } \\
\text { Sebelum } \\
\text { Sesudah } \\
\text { Selisih }\end{array}$ & $\begin{array}{l}45.10 \\
56.83 \\
11.733\end{array}$ & $\begin{array}{l}3.960 \\
3.270\end{array}$ & $\begin{array}{l}13.449 \\
10.018\end{array}$ & 13.991 & 0.000 \\
\hline & $\begin{array}{l}\text { Kel. Kontrol } \\
\text { Sebelum } \\
\text { Sesudah } \\
\text { Selisih }\end{array}$ & $\begin{array}{l}45.90 \\
45.70 \\
0.200\end{array}$ & $\begin{array}{l}3.652 \\
3.334\end{array}$ & $1.088-1.488$ & 0.318 & 0.753 \\
\hline
\end{tabular}

Hasil analisis menunjukkan terdapat perbedaan bermakna sikap kader pada kelompok intervensi sebelum dan sesudah intervensi (nilai $\mathrm{p}=0,000$ ), dengan selisih nilai rata-rata sebesar 11.733 Sedangkan pada kelompok control tidak ada perbedaan bermakna sikap kader (nilai $\mathrm{p}=0,753$ ). Pemberian intervensi berupa buku praktis tentang kesehatan ibu hamil dengan preeklamsia sangat berpengaruh terhadap sikap responden. Hal ini bertentangan dengan teori yang dikemukakan oleh Notoatmodjo (2012) bahwa pengetahuan merupakan hasil dari "tahu" dan ini terjadi setelah orang melakukan penginderaan terhadap suatu objek tertentu. Dalam hal ini objek yang diberikan adalah buku pedoman tentang kesehatan ibu hamil dengan preeklamsia. Dari pengetahuan yang bertambah tersebut, terwujud dalam sikap yang berupa menerima dan meresponnya, yang kemudian diejawantahkan dalam perilaku sehari-hari yang mendukung perubahan kepada hal yang lebih baik

Dalam hal ini, responden yang diberikan intervensi berupa pemberian buku pedoman kesehatan ibu hamil dengan preeklamsia, informasinya akan bertambah yang membuat responden menjadi lebih tahu. Dari pengetahuan tersebut akan memengaruhi sikap dan perilaku, dari budaya tidak sehat menjadi budaya sehat, yang akan mengakibatkan peningkatan kualitas hidup. Sebaliknya kelompok kontrol atau kelompok yang tidak diberikan tambahan informasi akan tetap dengan sikap dan perilakunya semula atau bahkan mengalami penurunan. Anonym. 2013 menyebutkan 
adanya kecenderungan semakin baik pengetahuan tentang hipertensi, diikuti semakin baik pula praktik pencegahan hipertensi.

Hasil penelitian ini sesuai dengan penelitian yang dilakukan oleh Ginting (2006) tentang hubungan antara pengetahuan dengan cara pencegahan hipertensi pada lansia, yang diperoleh hasil jumlah lansia yang berpengetahuan baik sebesar $63.9 \%$. Pengetahuan akan mendasar kepercayaan tentang suatu objek dan akan membentuk suatu kebiasaan, hal inilah yang kemudian akan memunculkan kemauan yang dimunculkan dalam sikap dan perilaku (Notoatmodjo, 2003).

Hal ini sesuai dengan Notoatmodjo (2003) bahwa pengetahuan adalah faktor penting yang mempengaruhi perilaku dan sesuai juga dengan penelitian yang dilakukan oleh Rosidi (2012) yang menyatakan bahwa terdapat hubungan antara tingkat pengetahuan keluarga dengan perilaku perawatan pada penderita hipertensi. Menurut Notoatmodjo (2010) faktor yang mempermudah atau mempredisposisi terjadinya perilaku salah satunya adalah pengetahuan. Jika seseorang mempunyai pengetahuan yang baik tentang hipertensi maka dia akan dapat mempraktikkan apa yang diketahui atau dinilai baik tersebut. Hasil penelitian ini sesuai dengan penelitian yang dilakukan oleh Andrian (2011) yang menyatakan bahwa ada hubungan antara tingkat pengetahuan tentang komplikasi hipertensi dengan perilaku pencegahan stroke.

Tabel 5. Pengaruh Karakteristik Responden Terhadap Sikap Kader

\begin{tabular}{ccccc} 
Variabel & B & P-value & Sd & T \\
\hline Pendidikan & 0.756 & 0.711 & 2.030 & 0.372 \\
Pekerjaan & 8.725 & 0.023 & 3.535 & 2.336 \\
Lama jadi kader & 3.725 & 0.043 & 1.800 & 2.070 \\
Konstanta & 14.093 & 0.083 & 7.976 &
\end{tabular}

Hasil analisis menunjukkan bahwa terdapat karakteristik kader yang memiliki hubungan bermakna dengan sikap kader, yaitu lama jadi kader dan pekerjaan kader. Menurut Mubarak
(2007) pekerjaan yang merupakan bagian yang dapat mempengaruhi pengetahuan seseorang. Menurut penelitian Mega, T.S dan Shobirun (2012) banyak ibu rumah tangga yang 
terkena hipertensi dibandingkan dengan ibu bekerja. Hal ini menurut Udjianti, (2010) merupakan salah satu faktor penyebab hipertensi adalah stress, karena pekerjaaan hanya mengurus rumah dan berbagai persoalan di rumah tangga.

Penelitian ini juga ingin membuktikan hasil penelitian lainnya yang menyatakan bahwa setiap intervensi yang dilakukan akan berpengaruh terhadap pengetahuan, sikap, dan perilaku responden. Sebagai contoh, penelitian yang dilakukan oleh Mustaking (2015) yang menyatakan bahwa terdapat pengaruh yang signifikan dari pemberian penyuluhan preeklamsia terhadap motivasi melakuan kunjungan ANC pada ibu hamil di Puskesmas Kasihan II Bantul. Dalam penelitiannya, Mustaking menyatakan bahwa ada pengaruh yang signifikan terhadap motivasi melakukan kunjungan ANC pada ibu hamil setelah diberikan intervensi berupa penyuluhan preeklamsia. Disamping itu Mega dan Sobhirun (2012) menegaskan setelah diberikan pendidikan kesehatan tentang hipertensi pengetahuan responden lebih baik dari sebelum diberikan tindakan menjadi $100 \%$, termasuk sikap meningkat menjadi 94,3\%. Kondisi ini didukung oleh Mubarak (2007) bahwa informasi dapat mempengaruhi pengetahunan seseorang dan Azwar (1997) dalam Utami (2009) bahwa media massa merupakan salah satu yang mempengaruhi sikap seseorang.

\section{SIMPULAN}

Terdapat pengaruh pada sikap kader antara kelompok intervensi dan kelompok kontrol setelah dilakukan intervensi. Variabel lama menjadi kader dan pekerjaan menjadi faktor yang mempengaruhi sikap kader. Penulis merekomendasikan ibu kader kesehatan untuk menggunakan buku pedoman kesehatan ibu hamil dengan preeklamsia dalam menjalankan tugasnya.

\section{UCAPAN TERIMA KASIH}

Peneliti mengucapkan terima kasih pada kader di Puskesmas Cipayung dan Cipinang Besar Utara dan berbagai pihak yang sudah terlibat dalam penelitian ini

\section{DAFTAR RUJUKAN}

Alimul, H. 2007.Riset dan Teknik Penulisan Ilmiah, Edisi Pertama, Salemba Medika, Jakarta

Al-Jameil, N., Aziz Khan, F., Fareed Khan, M., Tabassum, H. 2014. "A brief overview of preeclampsia.". Journal of clinical medicine research. Vol 6. No. 1. pp: 1-7. 
Anonim, 2014. Preeclampsia. Diunduh dari

http://www.mayoclinic.org/diseas es-conditions/preeclampsia/ pada hari Rabu, 24 Pebruari 2016, jam 08.45 .

Arulkumaran, N. \& Lightstone, L. 2013. "Severe pre-eclampsia and hypertensive crises". Best Practice \& Research Clinical Obstetrics \& Gynaecology. Vol. 27. No. 6. pp: 877-884.

Azwar, S. 2011. Sikap manusia: teori dan pengukurannya. Edisi 2. Jakarta: Pustaka Pelajar.

Brown, MC., et al. 2013. 'Women's perception of future riskfollowing pregnancies complicated bypreeclampsia', Hypertension in Pregnancy. Vol. 32, no. 1.pp. 6073 Available from: Informa Healthcare USA, Inc.

Depkes. 2014. Situasi kesehatan ibu. Infodatin. Jakarta: Depkes RI.

Depkes. 2012. Buku pedoman kader posyandu. Jakarta: Pusat Promosi Kesehatan Kementrian Kesehatan RI.

Diclemente, R.J., Salazar, L.F., \& Crosby, R.A. 2013. Health behavior theory for public health: principles, foundations, and applications. Burlington: Jones \& Bartlett Learning, Burlington.

Djannah, SN. \& Arianti, IS. 2010. "Gambaran epidemiologi kejadian preeklampsia/eklampsia di RSU PKU Muhammadiyah Yogyakarta Tahun 2009."ejournal.litbang.depkes.go. id/index.

Department of Health and Human Services. 2010. "Stages of pregnancy." Retrieved August 6, 2012, from http://womenshealth.gov/pregnan cy/you-are-pregnant/stages-ofpregnancy.html dari artikel "Pregnancy: Condition Information". Dari https://www.nichd.nih.gov/health/ topics/pregnancy/conditioninfo/Pa ges/default.aspx Diunduh hari Senin, 22 Pebruari 2016 jam 11.10 .

Departemen Kesehatan RI. 2010. "Praktis pelayanan antenatal terpadu." Kemenkes RI. Dirjen Bina Kesehatan Masyarakat. Jakarta.

East, C., Conway, K., Pollock, W., Frawley, N. \& Brennecke, S 2011 'Women's Experiences of Preeclampsia: Australian Action onPreeclampsia Survey ofWomen and Their Confidants', Journal of Pregnancy, Volume 2011, pp. 1-6. Available from: Hindawi Publishing Corporation.

Eisinga, R., te Grotenhuis, M. \& Pelzer, B. 2012. "The reliability of a two-item scale: Pearson, Cronbach, or Spearman-Brown.",International Journal of Public Health, terbit Agustus 2013, Volume 5._pp: 637642.

Farlex, 2012."Farlex Partner Medical Dictionary."

Kee-hak Lim. 2016. "Preeclampsia." Dari http://emedicine.medscape.com/ar ticle/261435-overview, diunduh 
hari Senin, 22 Pebruari 2016, jam 11.00 .

Kendell, R; Jablensky, A. 2003. "Distinguishing between the validity and utility of psychiatric diagnoses". The American Journal of Psychiatry. No. 160. Vol. 1. pp: 4-12.

Kumar, S.S. 2009. "Preeclampsia." http://www.academia.edu/771355 9/preeklampsia diunduh hari Rabu, 2 Maret 2016.

Meliono, Irmayanti, dkk. 2007. MPKT Modul 1. Jakarta: Lembaga Penerbitan FEUI.

Mikrajab, M. A. \& Rachmawaty, T. 2012. Peran kader kesehatan dalam program perencanaan persalinan dan pencegahan komplikasi pada ibu hamil di posyandu di kota Mojokerto, provinsi Jawa Timur. Jakarta: Buletin penelitian sistem kesehatan. Diunduh dari http://ejournal.litbang.depkes.go.i d/index.php/hsr/article/view/3046/ 3015 pada Rabu, 1 Februari 2017 jam 15.00.

Mustafa, R., Ahmed, S., Gupta, A., Venuto, RC. 2012.. "A Comprehensive Review of Hypertension in Pregnancy".Journal of Pregnancy. pp: 1-19.

Notoatmodjo, S. 2012. Promosi kesehatan \& ilmu penelitian. Edisi revisi 2012. Jakarta: PT. Rineka Cipta

Resnik, J.D.D.B. 2015. "What is Ethics in Research \& Why is it Important?" diunduh dari http://www.niehs.nih.gov/research /resources/bioethics/whatis/ pada Rabu, 2 Maret 2016, jam 17.00.

Olson, M. \& Kendrick, R. 2008. Attitides and attitude change. New York: Psychology Press Taylor \& Francis Group.

Sabri, L. \& Hastono, S.P. 2006. "Statistik Kesehatan: edisi revisi." Rajawali Pres. Jakarta.

Siti Nur Ramdaniati. 2008. "Pengetahuan dan sikap terhadap PHBS ibu RT Kelurahan Manggarai”. lib.ui.ac.id/file?file=digital/12265 1-S-5344-Pengetahuan\%20danHA...diunduh minggu, 27 Maret 2016, jam 23.30

Steegers, Eric AP, von Dadelszen, P., Duvekot, JJ., Pijnenborg, R. 2010. "Pre-eclampsia".The Lancetvol. 376 no. 9741. pp: 631-644.

Suhanda \& Evi. 2014. "Angka kematian ibu di Indonesia." Dari http://www.rri.co.id/post/berita/78 060/nasional/angka_kematian_ibu di_indonesia meningkat.html diunduh hari Selasa, 8 Maret 2016 jam 16.45 .

Sunaryo. 2014. Psikologi untuk keperawatan. Edisi 2. Jakarta: EGC.

Van der Linden, S. 2013. A response to Dolan. Princeton: Princeton University Publishing.

Vásquez, L., PulidoAcuña, C., Pulido, G., Montañez, C., Alexandra, R., 2014. 'Hazard, death and sequels: perception on severe preeclampsia 
b those who lived it', Enfermeria Gobal, no. 34. pp. 493-503.

WHO. 2014. Maternal mortality. Fact sheet no 348. Diunduh dari http://www.searo.who.int/thailand /factsheets/fs0024/en/ pada Rabu, 1 Februari 2017 jam 14.30.

Yahya, R. C. 2007. Pengertian, peran, dan fungsi kader kesehatan.
Diunduh dari https://www.jevuska.com/2007/06 /15/peran-dan-fungsi-kaderkesehatan/ pada Jumat, 3 Februari 2017, jam 11.00.

Yulifah R. 2009. Asuhan kebidanan komunitas. Jakarta: Salemba Medika. 